\title{
Review of: "A 400-Gb/s WDM-PAM4 OWC system through the free-space transmission with a water- air-water link"
}

\author{
Yahya Baykal ${ }^{1}$ \\ 1 Cankaya University
}

Potential competing interests: The author(s) declared that no potential competing interests exist.

It is a very good paper involving experimental insights of very high data bit rate OWC.

My comments are:

In what practical applications do we have the studied link architecture (200-m free-space transmission with 8.8-m piped water-air-piped water link/6.5-m turbid water-air-turbid water link) given in Fig. 5?

What is the reason in choosing PAM4. What is its advantage in the studied configuration.

How can the authors compare Figure 2 (a) with 2 (b), Figure $3(a)$ with 3 (b) and Figures 2 (a), 2 (b) with Figs. 3 (a), 3 (b)?

What is the main conclusion obtained in this work? 